\title{
DEVELOPMENT OF AZITHROMYCIN LOADED LEMONGRASS OIL BASED MICROEMULSION AND DETERMINATION OF ANTIBACTERIAL POTENTIAL
}

\section{ANDREW EBENAZER, JONATHAN SAMPATH FRANKLYNE, AMITAVA MUKHERJEE, N. CHANDRASEKARAN*}

\author{
Centre for Nanobiotechnology, Vellore Institute of Technology, Vellore 632 014, Tamil Nadu. India
}

Email: nchandrasekaran@vit.ac.in

Received: 21 Feb 2018, Revised and Accepted: 04 Sep 2018

\section{ABSTRACT}

Objective: Azithromycin (AZM), an azalide drug is used to treat bacterial infections. It is poorly water-soluble, with low human bioavailability due to partial absorption. This can be improved using a microemulsion drug delivery system using essential oil.

Methods: Microemulsion system was prepared with AZM solubilized lemongrass oil (Cymbopogon citratus), Tween 20 and water containing $1 \%$ $(\mathrm{v} / \mathrm{v}) 10 \mathrm{mmol}$ sodium hydroxide. In vitro drug release was determined using a $14 \mathrm{KDa}$ semipermeable dialysis membrane. The kinetics of bacterial killing was done at MIC concentrations, and viable counts were determined hourly for 24 h. Bacterial cell viability was determined by differential staining with acridine orange and ethidium bromide. In vitro toxicity was determined by the MTT assay, while in vivo toxicity was determined in male Wistar rats.

Results: The optimized formulation (5:20:75 \%) was thermodynamically stable with drug solubility of $366.90 \mathrm{mg} / \mathrm{ml}$ and a droplet diameter of $12.4 \pm 3.9 \mathrm{~nm}$, which do not show in vivo or in vitro toxicity. In vitro drug release study in simulated body fluids revealed a controlled drug release from microemulsion-based formulation. The MIC was $1 \mu \mathrm{g} / \mathrm{ml}$ and $2 \mu \mathrm{g} / \mathrm{ml}$ against Staphylococcus aureus and Escherichia coli respectively. In vitro kill kinetics showed $>2 \log _{10}$ killing by $8 \mathrm{~h}$. Bacterial cell viability assay and scanning electron microscopy analysis further confirmed substantial morphological changes due to alteration in the cell membrane.

Conclusion: The reduced droplet size and the inherent antibacterial property of lemongrass oil enhanced the efficacy of the AZM loaded ME system in comparison with the bulk drug, against the bacterial pathogens.

Keywords: Drug delivery system, lemongrass oil, Microemulsion, Drug release, Antibacterial activity, Toxicity testing

(C) 2018 The Authors. Published by Innovare Academic Sciences Pvt Ltd. This is an open-access article under the CC BY license (http://creativecommons.org/licenses/by/4.0/) DOI: http://dx.doi.org/10.22159/ijap.2018v10i6.25417

\section{INTRODUCTION}

Most of the new drugs currently in use are hydrophobic in nature [1], and their oral delivery is hindered by low oral bioavailability, lack of dose proportionality, high intra-and inter-subject variability, and short shelf life [2]. Recently, more attention is focused on oilbased or lipid-based formulations with a focus on self-micro emulsifying drug delivery system (SMEDDS) to improve these issues. SMEDDS, also termed as microemulsion (ME), are isotropic mixtures of essential oils and surfactants, with or without co-surfactants, which emulsify spontaneously or with gentle agitation on hydration to produce a transparent and homogeneous microemulsion $[3,4]$. They are thermodynamically stable, isotropic, clear dispersion, with high stability, low interfacial tension, and low viscosity [5]. Major advantage of ME includes improvement in drug solubility, enhancement of bioavailability, improvement in drug stability and prolonged shelf life [6].

This study describes the formulation and characterization of an oilin-water ME using lemongrass (Cymbopogon citratus, Family: Poaceae) oil (LG), a non-ionic surfactant and water. The main active components of LG oil for an aroma and taste are citral (65-86\%) [7], neral and geraniol. Each component has significant medicinal properties such as antidepressant, analgesic, antimicrobial [8], antiseptic, antipyretic, astringent, carminative, diuretic, deodorant, febrifuge, galactagogic, nervine, insecticidal and sedative $[9,10]$.

Azithromycin (AZM), an azalide antibiotic has its antibacterial activity due to a 15-membered aglycone ring with an additional nitrogen molecule [11]. It binds to a 50S subunit of the 70S bacterial ribosome and interferes with the elongation of the nascent polypeptide chain, which inhibits the RNA dependent protein synthesis in susceptible micro-organisms [12]. AZM is highly lipophilic and has a low oral bioavailability of $37 \%$. Acid degradation of the drug before absorption and possibly, incomplete absorption accounts for low bioavailability [13]. Hence, these limitations necessitates the need to improve the formulation by designing a more effective drug delivery system for AZM.

Hence, the aim of the study was to develop an AZM loaded LG oil-inwater $(\mathrm{o} / \mathrm{w})$ emulsion for improved delivery and efficacy of azithromycin.

\section{MATERIALS AND METHODS}

\section{Materials}

Azithromycin (AZM) was received from Aurobindo Pharma Limited, Hyderabad, India. Pure essential oil of lemongrass obtained from Falcon essential oils, Bengaluru, India. Tween 20 (Polyethylene glycol sorbitan monolaurate), and Tween 80 (Polyethylene glycol sorbitan monooleate) were obtained from Sigma-Aldrich, Bengaluru, India. Span 20, Span 80, Cremophor EL, brain heart infusion agar, Mueller Hinton agar, Staphylococcus aureus (ATCC 25923) and Escherichia coli (ATCC 25922) were obtained from Himedia laboratories private Ltd, Chennai, India. Sodium hydroxide pellets $(\mathrm{NaOH})$ obtained from SRL private limited, Mumbai, India. For all experiments, ultrapure water (Cascada Biowater System, USA) with a resistivity of not less than $18.2 \mathrm{M} \Omega / \mathrm{cm}$ was used. All other reagents used were of analytical grade.

\section{Solubility study}

The drug solubility of AZM was determined in various oils and surfactants (table 1) by the equilibration method. An excess amount of drug was added to $1 \mathrm{ml}$ of the selected oil or surfactant and vortexed to facilitate the solubilization. The vials were sealed and kept in an orbital shaker (Orbitek, Scigenics Biotech, India) for $72 \mathrm{~h}$ at $24 \pm 1{ }^{\circ} \mathrm{C}$ to attain equilibrium. Each vial was centrifuged at $600 \times \mathrm{g}$ for $15 \mathrm{~min}$, and the drug-saturated supernatant was filtered through a $0.45 \mu \mathrm{m}$ membrane filter. The final concentration of the drug in the filtrate was determined using a UV-visible spectrophotometer (U2910, Hitachi, Japan) after appropriate dilution with carbinol $[14,15]$. 


\section{Selection of surfactant}

The surfactant used for the preparation of ME formulation depends on its hydrophilic-lipophilic balance (HLB) value and non-toxic nature. Non-ionic surfactants like polysorbates (Tween 20, Tween 80), sorbitan esters (Span 20, Span 80), and Cremophor EL were chosen. These surfactants were examined for highest emulsification efficiency with the selected oil showing maximum solubility. Selection of surfactant was made on the basis of percentage transparency and ease of emulsification. An equal amount of each surfactant and LG oil was mixed individually. The mixture was gently heated to $45-50{ }^{\circ} \mathrm{C}$ to attain homogenization. 100 al of each mixture was diluted in $50 \mathrm{ml}$ ultrapure water in a separate glass stoppered conical flask. The level of emulsification was determined by counting the required number of flask inversions to give a clear homogeneous emulsion by observing visually. The percentage transparency (\%) of the resulting emulsions were examined at 600 $\mathrm{nm}$ by a UV spectrophotometer taking ultrapure water as a blank and reference [16]. The surfactant producing a clear emulsion with the least number of inversions and maximum transparency was selected for the further analysis.

\section{Pseudo-ternary phase diagram}

Two groups of oil and surfactant mixture with different combinations were determined, and the pseudo-ternary phase diagram was made using the water titration method according to Syed HK et al [17]. The first group contains combination of oil and surfactant mixture ratios as $1: 1,1: 2,1: 3,1: 4,1: 5,1: 6,1: 7,1: 8$ and $1: 9$ $(\mathrm{v} / \mathrm{v})$, and another group of combination contain 1:9, 2:8, 3:7, 4:6, $5: 5,6: 4,7: 3,8: 2$ and 9:1 (v/v). Ultrapure water was added gradually to each mixture and visual transformation of the sample from turbid to transparent and reverse was noticed to determine the phase appearance. The areas and boundaries at which the clear and transparent microemulsion domains obtained from the endpoint composition of the titrated samples were determined with the aid of plotting the pseudo-ternary phase diagram, using Origin Pro 8.5.0 (Origin Lab Corporation, USA). Experiments were performed in triplicate, to confirm reproducibility [15].

\section{Preparation of Microemulsion}

The clear monophasic region plotted in phase diagram delineates the ME domain. The ratio at which the transparent and clear formulation obtained with minimal surfactant concentration was identified [18]. 1\% (w/v) Azithromycin (AZM), solubilized in LG oil was used to prepare the drug-loaded ME formulation (LGME-AZM) with the optimized ratio obtained from the preliminary study. To study the phase behavior of the ME region, two group of formulations were prepared with different oil to surfactant ratios, making up to $100 \%$ with an aqueous phase containing water with $1 \%(\mathrm{v} / \mathrm{v}) 10 \mathrm{mmol} \mathrm{NaOH}$ [19]. Visual appearance of the obtained formulations with a change from turbid to translucent was observed.

\section{Thermodynamic stability study}

The thermodynamic stability of LGME-AZM formulations that appears transparent visually was examined under the extreme stress conditions [20]. Centrifugation was done at $1500 \mathrm{x}$ g for $30 \mathrm{~min}$ to ensure physical stability. The stable, transparent formulations were cooled to $4{ }^{\circ} \mathrm{C}$ alternating with heating at $45^{\circ} \mathrm{C}$ for $48 \mathrm{~h}$ at each temperature, repeated for six cycles. The formulations that remain stable were then subjected to freeze-thaw conditions. Here, the formulations were taken on to three cycles of $-21^{\circ} \mathrm{C}$ and $+25^{\circ} \mathrm{C}$ for $48 \mathrm{~h}$ each. The formulations that remain transparent with no phase separation were taken for further characterization [15].

\section{Characterization of optimized ME}

Characterization of all samples was performed in triplicate. Experiments were performed at $25 \pm 1{ }^{\circ} \mathrm{C}$ and results were represented as mean \pm SD.

\section{(a) $\mathrm{pH}$ measurement}

The $\mathrm{pH}$ value of thermodynamically stable, clear and transparent formulation was determined using a calibrated $\mathrm{pH}$ meter (Systronics, India).

\section{(b) Conductivity measurement}

Electrical conductivity $(\sigma)$ was a reliable and convenient method to investigate the structural features of ME. The conductivity measurement helps in determining the nature of the continuous phase of the ME system [21]. The electro-conductivity $(\sigma)$ of the formulated sample was evaluated using a conductivity meter (CM 180, Elico, India).

\section{(c) Turbidity determination}

The turbidity of the translucent formulations were analyzed by measuring the absorbance at a visible wavelength $(600 \mathrm{~nm})$ using a UV-visible spectrophotometer with ultrapure water as blank and reference.

\section{(d) Viscosity determination}

The viscosity reading was measured using a spindle viscometer (DV3TLVT, Brookfield Inc., USA) equipped with spindle no. 18.

\section{Size analysis}

\section{(a) Droplet size determination}

The ME droplet size and the polydispersity index (PI) was analyzed by dynamic light scattering (DLS) technique using nanoparticle analyzer (SZ-100 Horiba, Japan). The particle size of the optimized LGME-AZM formulation was determined using a diode pumped frequency double laser at $532 \mathrm{~nm}(10 \mathrm{~mW})$ light scattering at an angle of $173^{\circ}$. Data acquisition and analysis was performed using the software provided by the manufacturer.

\section{(b) Zeta potential determination}

To determine zeta potential, the transparent ME was analyzed using a nanoparticle analyzer. This analysis was based on the electrophoretic mobility $\left(\mathrm{cm}^{2} / \mathrm{V}-\mathrm{s}\right)$ of the particles, that gets converted to as zeta potential $(\mathrm{mV})$, which was measured using the software provided.

\section{In vitro release studies}

The in vitro drug release of AZM from the optimized LGME-AZM was performed by diffusion study using dialysis membrane and the diffusion medium containing simulated body fluids, prepared according to U. S. Pharmacopeia (USP) [22]. Dialysis membrane was filled with LGME-AZM (equivalent to 2 mg AZM) and AZM bulk drug suspension $(2 \mathrm{mg}$ ) separately, and the ends were sealed. Both of these dialysis bags were immersed into $180 \mathrm{ml}$ of simulated gastric fluid $(\mathrm{pH}$ $1.2)$, and simulated intestinal fluid ( $\mathrm{pH} 6.8)$, at $37 \pm 1^{\circ} \mathrm{C}$ with a $50 \mathrm{rpm}$ rotating speed. Sample $(1 \mathrm{ml})$ was withdrawn at regular time intervals (1-8 h), and an equal volume of the respective fluid was added to uphold the constant volume. The sample withdrawn was filtered using a $0.45 \mu \mathrm{m}$ filter and the amount of drug release at each time interval was determined using UV visible spectrophotometric method [23]. All the experimental readings were noted in triplicate.

\section{Antibacterial activity}

\section{(a) Bacterial inoculum}

The antibacterial activity of LGME-AZM was assessed against Staphylococcus aureus ATCC 25923 and Escherichia coli ATCC 25922, preserved at $-80{ }^{\circ} \mathrm{C}$ in brain heart infusion (BHI) broth with $10 \%$ (v/v) glycerol. The bacterial cultures were revived onto BHI agar plates at $37 \pm 1{ }^{\circ} \mathrm{C}$ incubated overnight, and the bacterial colonies grown were suspended in sterile physiological saline $(0.85 \% \mathrm{NaCl})$, to obtain culture suspensions for the anti-bacterial studies.

\section{(b)Minimum inhibitory concentration (MIC) determination using resazurin assay}

The MIC value of the LGME-AZM against $S$. aureus and E. coli was determined using resazurin-microtiter plate method (96-well plate technique) with slight modification as reported earlier in Elshikh et al., 2016 [24]. This method was adopted owing to its precise and sensitive results to compare the earlier results. The MIC was determined according to the clinical and laboratory standards institute (CLSI) protocols [25]. Resazurin was prepared at $0.015 \%$ 
$(\mathrm{w} / \mathrm{v})$, filter sterilized $(0.45 \mu \mathrm{m}$ filter $)$ and stored at $4{ }^{\circ} \mathrm{C}$. After overnight incubation at $37 \pm 1{ }^{\circ} \mathrm{C}, 10 \%(\mathrm{v} / \mathrm{v})$ of prepared resazurin dye was added to each well and incubated at $37 \pm 1{ }^{\circ} \mathrm{C}$ for $2 \mathrm{~h}$. The change in color from blue to pink was observed. The lowest concentration is showing the complete absence of pink color was expressed as the MIC of the tested sample against the particular strain and expressed in $\mu \mathrm{g} / \mathrm{ml}[24,26]$.

\section{Time-kill assay}

Time-Kill assay also known as the suspension time-kill analysis determines the in vitro antimicrobial activity of the test sample in relation to time. AZM bulk suspension and LGME-AZM were tested against each bacterial strain (inocula similar to MIC inocula) at $0.5 \mathrm{x}$, $1 \mathrm{x}$ and $5 \mathrm{x}$ MIC. The viability of treated strains and suitable controls were determined by dilution and plating onto sterile BHI Brain heart infusion (BHI) agar plates incubated overnight at $37 \pm 1^{\circ} \mathrm{C}$.

\section{(c) Determination of cell viability}

The cell viability assay was performed using acridine orange (AO) and ethidium bromide (EtBr) double staining method to distinguish the live and dead bacterial cells after treatment [27]. The level of membrane disintegration of $S$. aureus and $E$. coli after being treated with $1 \mathrm{x}$ MIC of LGME-AZM was observed under fluorescent microscopy. The culture inoculum $\left(1 \times 10^{8} \mathrm{CFU} / \mathrm{ml}\right)$ interacted with the $1 \mathrm{x}$ MIC of the test sample prepared accordingly with phosphate buffer saline (PBS). The treated bacterial cultures were washed with PBS by centrifugation to obtain a pellet. $4 \mu \mathrm{l}$ each of AO (15 $\mu \mathrm{g} \cdot \mathrm{ml}^{-1}$ in PBS) and EtBr $\left(50 \mu \mathrm{g} \cdot \mathrm{ml}^{-1}\right.$ in PBS) stain was added to the pellet, vortexed and kept for incubation, for 10 min. The unbound dyes were removed after centrifugation and pellet was re-suspended in PBS. The images were analyzed and captured using fluorescence microscope (DM-2500, Leica Microsystems, USA) equipped with a digital camera (DFC-295, Leica Microsystems, USA) and processed with Leica Application Suite 3.8 [15].

\section{(d) Scanning electron microscopy (SEM)}

The bacterial cell suspension of both bacterial strains (S. aureus and $E$. coli) at $1 \times 10^{8} \mathrm{CFU} / \mathrm{ml}$ in PBS was treated with LGME-AZM at $1 \mathrm{x}$ MIC for $18 \mathrm{~h}$. Untreated bacterial suspensions were used as negative controls. The cells were harvested by centrifuging at $2000 \mathrm{xg}$ for $10 \mathrm{~min}$. The cells in the pellet were coated onto a glass slide $\left(1 \mathrm{~cm}^{2}\right)$, air dried and dipped in $2.5 \%$ glutaraldehyde for $2 \mathrm{~h}$ to fix the cells. Further, the cells were dehydrated in a solution containing increasing concentrations of ethanol $(30 \%, 50 \%, 70 \%$, and $99.9 \%)$ for $10 \mathrm{~min}$ each [28]. The process of sputter coating with an ultra-thin electrically conducting metal, gold/palladium $(\mathrm{Au} / \mathrm{Pd})$ was placed onto the specimen on a glass slide, prior to SEM imaging. The surface morphology of the samples was observed under high-resolution SEM (EVO18 Research, Zeiss, Germany).

\section{Toxicity studies}

\section{(a) In vitro toxicity testing}

Fresh blood was collected in the heparinized tube from a healthy human donors $(n=6)$, according to the institutional guidelines, with the reference number VIT/IECH/014/Jan24.2015. Lymphocytes, a peripheral blood mononuclear cell (PBMC) were separated using lymphocyte separation media $\left(\mathrm{HiSep}^{\mathrm{TM}}\right.$, HiMedia, India) by density gradient separation technique [29]. Isolated lymphocytes were resuspended in RPMI 1640 media and stored at $4{ }^{\circ} \mathrm{C}$. The human lymphocytes $\left(1 \times 10^{4}\right.$ cells $\left./ \mathrm{ml}\right)$ in RPMI 1640 was treated with optimized LGME system and LGME-AZM; and also with the individual components (LG oil, Tween 20) at various concentrations (50\%, 25\%, and $12.5 \%)$. These were incubated overnight at $37 \pm 0.5$ ${ }^{\circ} \mathrm{C}$ with $5 \% \mathrm{CO}_{2}$. About $20 \mu \mathrm{l}$ per well of $0.5 \%$ (w/v) MTT solution was mixed with the treated cells and incubated at $37 \pm 1{ }^{\circ} \mathrm{C}$ for $4 \mathrm{~h}$. After incubation, $50 \mu \mathrm{l}$ of dimethyl sulfoxide (DMSO) was added, and the absorbance reading was measured using PowerWave XS2 microplate reader (BioTek Corp, USA) at a visible wavelength. The percentage of cell viability was represented as mean \pm SD [30]

\section{(b) In vivo acute and sub-acute toxicity testing}

Animal studies were done to determine the in vivo toxicity testing of the novel drug formulation. Ethical approval (VIT/IAEC/10 th $/$ March $14^{\text {th }} /$ No.04) was obtained from the Institutional Animal Ethical Committee (IAEC, VIT Vellore) following guidelines of Committee for the Purpose of Control and Supervision of Experiments on Animals (CPCSEA, India). The study was done to assess the toxicity of drug loaded ME by acute and sub-acute toxicity in male Wistar rats according to the Organisation for Economic Co-operation and Development (OECD) guidelines 423 and 407. This testing includes analysis for biochemical markers, hematological and histopathological changes observed due to oral administration. Before experimentation, Wistar rats (4-6 w) were provided with food and water ad libitum and housed at $26 \pm 2{ }^{\circ} \mathrm{C}$ in the animal house for acclimatization for $1 \mathrm{w}$. Rats were divided into three groups ( $\mathrm{n}=6$ per group) as LGME system, LGME-AZM, and healthy control group respectively. About $1 \mathrm{ml} / \mathrm{kg}$ body weight of the respective test samples were administered orally by oral gavage, except to the healthy control group. After the final administration, animals were weighed and euthanized by asphyxiation with $\mathrm{CO}_{2}$ gas. Blood sample withdrawn and serum/plasma was separated. Complete blood count (CBC) was analyzed. Blood enzymes such as aspartate aminotransferase (AST) and alanine aminotransferase (ALT) was measured to assess the liver function, and creatinine was measured for kidney function evaluation [31]. Dissection procedure was done, and the organs such as liver and small intestine were removed, and fixed in $10 \%$ buffered formalin solution for histopathological studies. Tissue sections $(6 \mu \mathrm{m})$ were sectioned, stained with hematoxylin-eosin (HandE), and visualized under an optical microscope to study the hepatotoxicity and nephrotoxicity.

\section{Statistical analysis}

All experiments were performed in triplicate and results represented as mean \pm SD. All calculations and graphs were drawn using Microsoft Excel 2016 (Microsoft Corporation, USA).

\section{RESULTS AND DISCUSSION}

\section{Selection of components}

To develop a biocompatible oral drug delivery system for AZM, varied components were picked from the generally regarded as safe (GRAS) category. Favorably, the oil-in-water ME acts as a major vehicle in the incorporation of the hydrophobic drug, which thus leads to improved solubility, maintains stability and exhibits an improved drug diffusion in vivo [15]. The oil system in ME helps in drug maintenance in its solubilized form. The solubility of AZM in varied oils and surfactants were depicted in table 1 . Based on the maximal solubility of AZM in lemongrass oil $(366.90 \mathrm{mg} / \mathrm{ml})$, this was preferred as the relevant oil system for the preparation of ME formulation.

Table 1: Solubility of azithromycin in oils and surfactants

\begin{tabular}{ll}
\hline Oil & Solubility* $\mathbf{m g} / \mathbf{m l})$ \\
\hline Lemongrass & $366.90 \pm 2.98$ \\
Olive & $1.89 \pm 0.05$ \\
Peppermint & $253.50 \pm 4.77$ \\
Castor & $20.19 \pm 1.07$ \\
Cremophor EL & $31.73 \pm 0.42$ \\
Tween 20 & $8.17 \pm 0.13$ \\
Tween 80 & $6.08 \pm 0.08$ \\
Basil & $256.02 \pm 1.82$ \\
Turmeric & $26.80 \pm 1.28$ \\
Thyme & $161.62 \pm 1.44$ \\
Rosemary & $144.56 \pm 1.01$ \\
\hline
\end{tabular}

$(*$ Values with mean $\pm S D, n=3$ ) 


\section{Selection of surfactant}

Non-ionic surfactants including polysorbates (Tween 20, Tween 80), sorbitan esters (Span 20, Span 80), and cremophor EL were screened for higher emulsification efficiency. Tween 20 showed highest emulsification efficiency for lemongrass oil, with maximum transparency and least number of flask inversions in comparison with the other surfactants as shown in table 2. Non-ionic surfactants, especially tween 20 and tween 80 were most commonly used to diffuse hydrophobic particles in aqueous solutions. As tween 20 shows maximum emulsification with LG oil, it was preferred to use in preparation of oil-in-water ME. Existing research favouring tween 20 in drug delivery system explains the surfactant as more biocompatible, minimally toxic, less haemolytic and reduced level of irritation to cellular surfaces and able to maintain physiological $\mathrm{pH}$ in solutions $[32,33]$.

Table 2: Emulsification efficiency of surfactants

\begin{tabular}{|c|c|c|}
\hline Surfactant & \% Transparency* & No. of inversions* \\
\hline Tween 20 & 99.98 & 02 \\
\hline Tween 80 & 98.98 & 04 \\
\hline Span 20 & 99.83 & 20 \\
\hline Span 80 & 99.80 & 20 \\
\hline Cremophor EL & 99.98 & 09 \\
\hline
\end{tabular}

${ }^{*}$ Values with mean $(\mathrm{n}=3)$

\section{Pseudo-ternary phase diagram}

Pseudo-ternary phase diagram was constructed using water titration method to describe the region of clear microemulsions and provide a greater understanding on the relation between phase behavior of the emulsion and its varying compositions. A pseudoternary phase diagram of the investigated ternary system LG oil/Tween 20/water was plotted (fig. 1). Formation of visually transparent ME system (black spotted points) was observed at room temperature. Phase behavior determination was indicated as the suitable approach to determine the oil phase, surfactant and aqueous phase concentration, with which the transparent, homogenous, and low-viscous ME system was formed. This plotting reveals the possibility of ratios at which the maximum proportion of oil was incorporated with less composition of surfactant $(<50 \%)$ to give the homogenous ME systems [34].
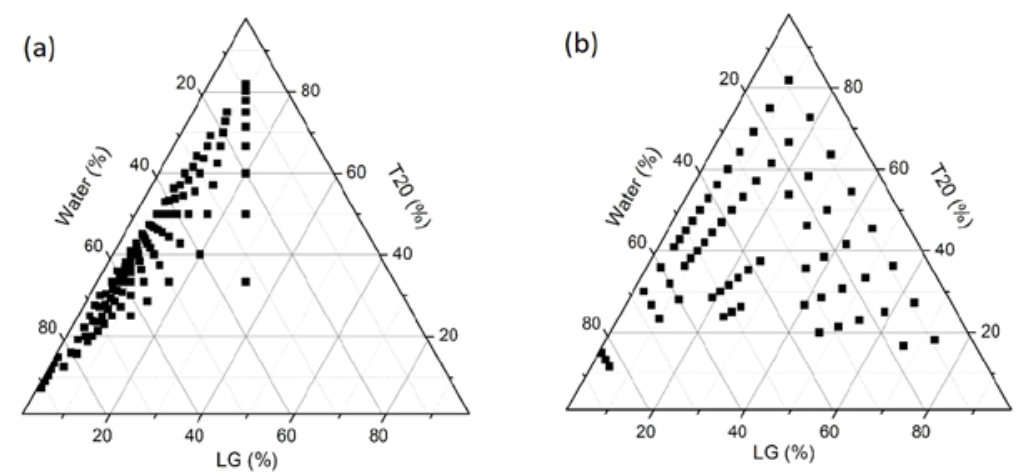

Fig. 1: Pseudo-ternary phase diagrams done with lemongrass oil/tween 20/water. (a) ME transparent region between oil and surfactant ratio 1:1 to 1:9 (b) ME transparent region between oil and surfactant ratio 1:9 to 9:1

\section{Optimization of the drug loaded microemulsion}

The phase study reveals the maximum proportion of oil with a minimal concentration of surfactant to give a monophasic clear ME. The higher oil content in ME may provide an ability to incorporate a larger quantity of AZM. Moreover, when the percentage of surfactant in a ME preparation was $<50 \%$, the formulation was less viscous and minimizes the toxicity. According to these phenomena, the formulation showing transparent ME containing LG oil (5\%), tween $20(20 \%)$, and water $(75 \%)$ was chosen from the phase study. Fig. 2 shows the visual appearance of all the formulations with LG oil/tween 20/water. It was necessary to determine the lowest concentration of surfactant (Tween 20) to form a clear homogenous formulation. The concentration of oil and water was kept constant respectively in each set of formulations prepared as shown (fig. 2a and $2 \mathrm{~b}$ ). The $\mathrm{pH}$ of formulations ranged between 4.8 and 5.8. As this might affect drug absorption in oral drug delivery, $1 \%$ of $10 \mathrm{mmol}$ $\mathrm{NaOH}$ was added to the aqueous phase of the optimized ME to maintain a neutral $\mathrm{pH}$. The visual inspection of both sets of formulations shows that the formulation with higher interfacial tension shows a phase separation, with milky white to turbid denoted a biphasic region [15]. Whereas the formulations with less or reduced interfacial tension, as there was an increase in surfactant concentration showed transparent homogeneous formulations with no phase separation, which signifies the presence of an ME region. The clear and transparent formulations, 1:4 to $1: 9$ in $1^{\text {st }}$ set and 1:9 to $4: 7$ in the $2^{\text {nd }}$ set were subjected to accelerated thermodynamic stability tests to determine the optimized ME ratio.

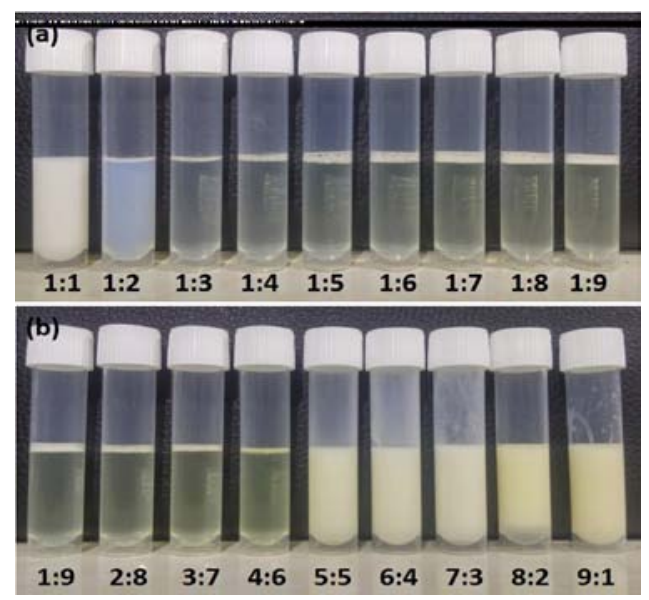

Fig. 2: Visual appearance of formulations from lemongrass oil/tween 20/water: Formulations with LG oil: surfactant ratio (a) $1: 1$ to $1: 9$ (b) $1: 9$ to $9: 1$ 


\section{Thermodynamic stability study}

All the transparent AZM loaded formulations were found to be physically stable (table 3 and table 4), except the formulations ( $1: 3$ and 4:6), which lost their stability and became turbid during the heating cycle. The transparent formulation (1:4) was formed with a minimal surfactant concentration and contain adequate oil concentration to solubilize drug. From this criterion, the optimized formulation of LGME-AZM (1:4) was determined to be with a LG oil/tween 20/water ratio of 5:20:75\%. This optimized formulation of AZM was thermodynamically stable.

Table 3: Observations of the thermodynamic stability tests of formulations with lemongrass oil/tween 20 ratio (1:1 to 1:9)

\begin{tabular}{llll}
\hline O/S Ratio & O: S: W (\%) & CENTRF & Heating /Cooling \\
\hline $1: 1$ & $5: 5: 90$ & X & X \\
$1: 2$ & $5: 10: 85$ & X & X \\
$1: 3$ & $5: 15: 80$ & Clear & Turbid \\
$1: 4$ & $5: 20: 75$ & Clear & Clear \\
$1: 5$ & $5: 25: 70$ & Clear & Clear \\
$1: 6$ & $5: 30: 65$ & Clear & Clear \\
$1: 7$ & $5: 35: 60$ & Clear & Clear \\
$1: 8$ & $5: 40: 55$ & Clear & Clear \\
$1: 9$ & $5: 45: 50$ & Clear & Clear \\
\hline
\end{tabular}

(O-Lemongrass oil, S-Surfactant, W-Water, CENTRF-Centrifugation)

Table 4: Observations of the thermodynamic stability tests of formulations with lemongrass oil/tween 20 ratio (1:9 to 9:1)

\begin{tabular}{|c|c|c|c|c|}
\hline 0/S Ratio & 0: S: W (\%) & CENTRF & Heating / Cooling & Freeze /Thaw \\
\hline $1: 9$ & $5: 45: 50$ & Clear & Clear & Clear \\
\hline $2: 8$ & $10: 40: 50$ & Clear & Clear & Clear \\
\hline $3: 7$ & $15: 35: 50$ & Clear & Clear & Clear \\
\hline $4: 6$ & $20: 30: 50$ & Clear & Turbid & $\mathrm{x}$ \\
\hline $5: 5$ & $25: 25: 50$ & $\mathrm{x}$ & $\mathrm{x}$ & $\mathrm{x}$ \\
\hline $6: 4$ & $30: 20: 50$ & $\mathrm{x}$ & $\mathrm{x}$ & $\mathrm{x}$ \\
\hline $7: 3$ & $35: 15: 50$ & $\mathrm{x}$ & $\mathrm{x}$ & $\mathrm{x}$ \\
\hline $8: 2$ & $40: 10: 50$ & $\mathrm{x}$ & $\mathrm{x}$ & $\mathrm{x}$ \\
\hline 9:1 & $45: 5: 50$ & $\mathrm{x}$ & $\mathrm{x}$ & $\mathrm{x}$ \\
\hline
\end{tabular}

(O-Lemongrass oil, S-Surfactant, W-Water, CENTRF-Centrifugation)

\section{Physicochemical characterization}

\section{(a) pH, conductivity, turbidity and viscosity measurement}

The $\mathrm{pH}$ of the optimized thermodynamically stable LGME-AZM (1:4) was found to be $6.54 \pm 0.005$. The $\mathrm{pH}$ did not vary significantly with storage due to the presence of non-ionic surfactant in the system. Its electrical conductivity $(\sigma)$ was $0.274 \pm 0.001 \mu \mathrm{S} / \mathrm{cm}$. The higher water concentration $(75 \% \mathrm{v} / \mathrm{v})$ showed an increase in electrical conductivity, which clearly confirms the oil-in-water nature of the ME. Quantitative measurement of the optical transparency of optimized LGME-AZM in the visible wavelength $(600 \mathrm{~nm})$ shows absorbance of less than $0.010 \pm 0.001$. The percent transmission was found to be more than $90 \%$ which confirms the homogenous nature of ME. The viscosity determination on the drug-loaded formulations was observed to be very low $(5.69 \mathrm{cP} \pm 0.20)$, due to the homogeneous nature of ME [35].

\section{Size analysis}

\section{(a) Droplet size interpretation}

The principle of DLS analysis was based on the particle diffusion due to Brownian motion, gives the basic detail of the particle size [36]. The DLS technique was appropriate to study the colloidal dispersions. The mean droplet size of the optimized LGME-AZM (1:4) was $12.4 \pm 3.9 \mathrm{~nm}$ (fig. 3). Smaller droplet size of the drugloaded ME has vital importance in drug delivery system, as this determines the degree and intensity of drug release, which was directly related to the drug absorption [16]. The polydispersity index (PDI) illustrates the quality or homogeneity of the dispersion [37]. The mean PDI of LGME-AZM (1:4) formulation was $0.4 \pm 0.001$. This result shows that the formulation with a very low PDI illustrates the homogeneous size distribution of the droplets. This clearly explains that the particle distribution was one of the mechanisms that controls the stability of the ME, as the uniform distribution of ME droplets provides better stability [15].

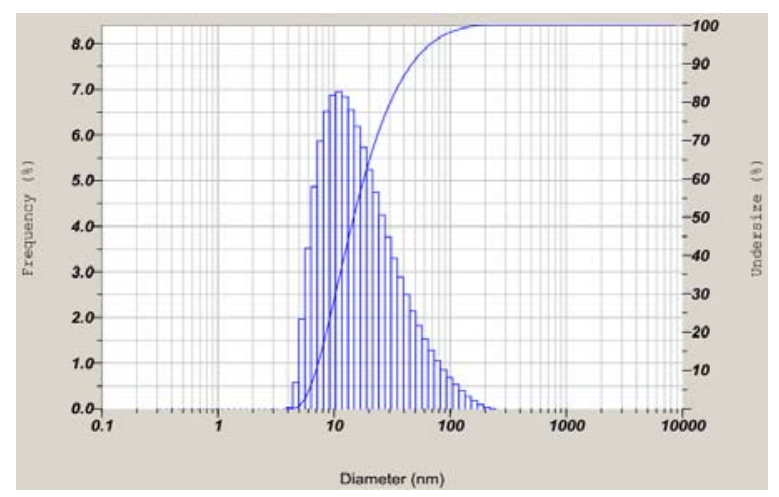

Fig. 3: Droplet size analysis of optimized LGME-AZM (1:4)

\section{(b) Zeta potential measurement}

The droplets or particles in an emulsion carries an electrical charge. Zeta (द) potential was explained as the difference in potential between the tight bound layer of the droplets surface and the electroneutral region of an emulsion [38]. The zeta potential of the optimized LGME-AZM (1:4) formulation was found to be- $13.9 \pm 0.42$ $\mathrm{mV}$. The amount of charge on the particle surface was an important characteristic to determine the stability of an emulsion, as $\zeta$ potential controls, the extent of repulsion between the adjacent, similarly charged, dispersed droplets. The decrease in $\zeta$-potential induces the attractive forces to exceed the repulsive force, which might lead to the aggregation of droplets [39].

\section{In vitro release studies}

In vitro drug release from LGME-AZM and AZM bulk drug suspension was done by dialysis method using dialysis membrane. The amount of 
drug release obtained by the dialysis method provides an indirect correlation with the in vivo drug release [40]. The in vitro release action of the LGME-AZM and AZM bulk drug suspension was summarized as cumulative percentage release as shown in fig. 4 . In simulated intestinal fluid after $8 \mathrm{~h}$, about $64.79 \pm 1.61 \%$ of the drug was released in case of LGME-AZM, while pure AZM drug showed only $18.74 \pm 0.49 \%$ of diffusion profile. In the same way, in the case of simulated gastric fluid after $8 \mathrm{~h}$, about $36.2 \pm 1.95 \%$ of the drug was released in case of LGME-AZM, while plain drug showed only
$7.08 \pm 0.16 \%$ of diffusion. The release studies were conducted for $8 \mathrm{~h}$ to observe the deviation or existence of precipitation over time. The in vitro drug release studies indicate that the formulation of AZM in the form of LGME-AZM formulation enhances the drug diffusion properties. It was observed that the total percentage of drug diffusion was much higher in ME system than pure drug suspension in both simulated body fluids. The drug diffusion from ME was observed to be higher in the intestinal fluid than the gastric fluid, which explains to be advantageous for increased drug absorption [41].
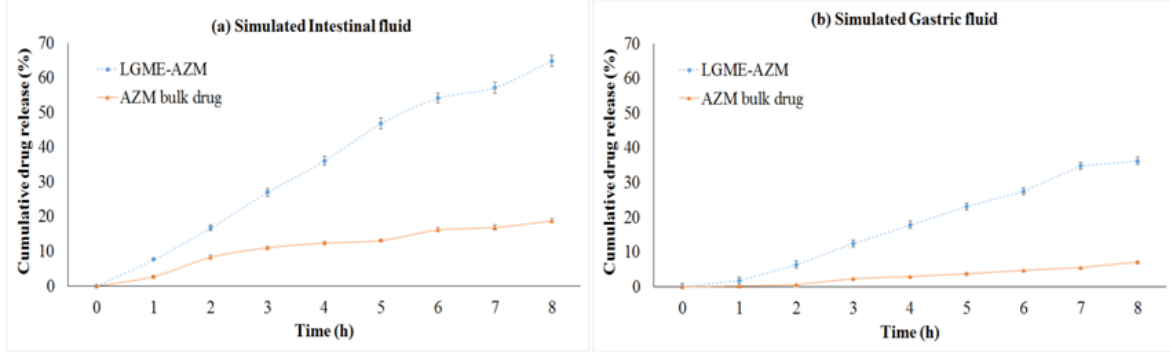

Fig. 4: Cumulative drug release (\%) of LGME-AZM and AZM pure drug suspension in relevant dissolution medium (a) Simulated intestinal fluid (b) Simulated gastric fluid

\section{Antibacterial activity}

\section{Minimum inhibitory concentration (MIC)}

Resazurin micro titre plate method was done to determine the minimum inhibitory concentration. The antimicrobial activity of both optimized LGME-AZM and AZM bulk drug suspension was assessed against two bacterial strains, S. aureus, and E. coli. The MIC value was read by visual observation in a change of colour in the wells. At higher concentrations of drug interaction with bacterial strains, blue coloration was observed to indicate that all microbial cells were killed or inhibited. At lower concentrations of the drug, the wells appear pinkish, which indicates the growth of the microbial culture. The least or minimum concentration that inhibited or killed the microbial growth (blue colour) was considered as the MIC $(\mu \mathrm{g} / \mathrm{ml})$ value for the tested compounds, respectively. In the case of $S$. aureus, the MIC value of AZM bulk drug suspension and LGME-AZM was found as $4 \mu \mathrm{g} / \mathrm{ml}$ and $1 \mu \mathrm{g} / \mathrm{ml}$ respectively. For E. coli, the inhibition for AZM bulk drug suspension and LGME-AZM was found to be $4 \mu \mathrm{g} / \mathrm{ml}$ and $2 \mu \mathrm{g} / \mathrm{ml}$ respectively. From the results obtained, it clearly states that the optimized LGME-AZM formulation showed two-fold increase in antibacterial activity against $S$. aureus and a single fold increase for $E$. coli, in comparison with the conventional pure AZM drug.

\section{Time-Kill kinetics assay}

The resulting data for the Time Kill assay was typically presented graphically (fig. 5), where the colony counts for each antimicrobial agent was plotted against the concentration tested at each time point $(0-8 \mathrm{~h})$. The optimized LGME-AZM and AZM bulk drug suspension was tested at $0.5 \mathrm{x}, 1 \mathrm{x}$ and $5 \mathrm{x}$ of its MIC obtained from the previous study. Here, the viable colony counts $(\mathrm{CFU} / \mathrm{ml})$ was observed at each time interval with each concentration. Fig. 5 clearly shows that the LGME-AZM at $1 \mathrm{x}$ and $5 \mathrm{x}$ MIC was able to decrease the viable counts of both bacterial strains, $S$. aureus, and E. coli by $>2 \log _{10}$ within $8 \mathrm{~h}$. It explains that the bacterial strains were more susceptible to the optimized LGME-AZM at $1 \mathrm{x}$ and $5 \mathrm{x}$ MIC in comparison with the AZM bulk drug form at the same MIC. $5 x$ MIC of LGME-AZM acts completely bactericidal by $8 \mathrm{~h}$. At higher MIC, ME acts as bactericidal; whereas in reduced MIC, enhanced growth was observed. Based on the mechanism of action, protein synthesis inhibitors such as macrolides (AZM) are considered as bacteriostatic agents, which suppresses bacterial growth. Bacterial strains that are exposed to those antibiotics at the MIC or higher can grow again after antibiotic elimination [42].

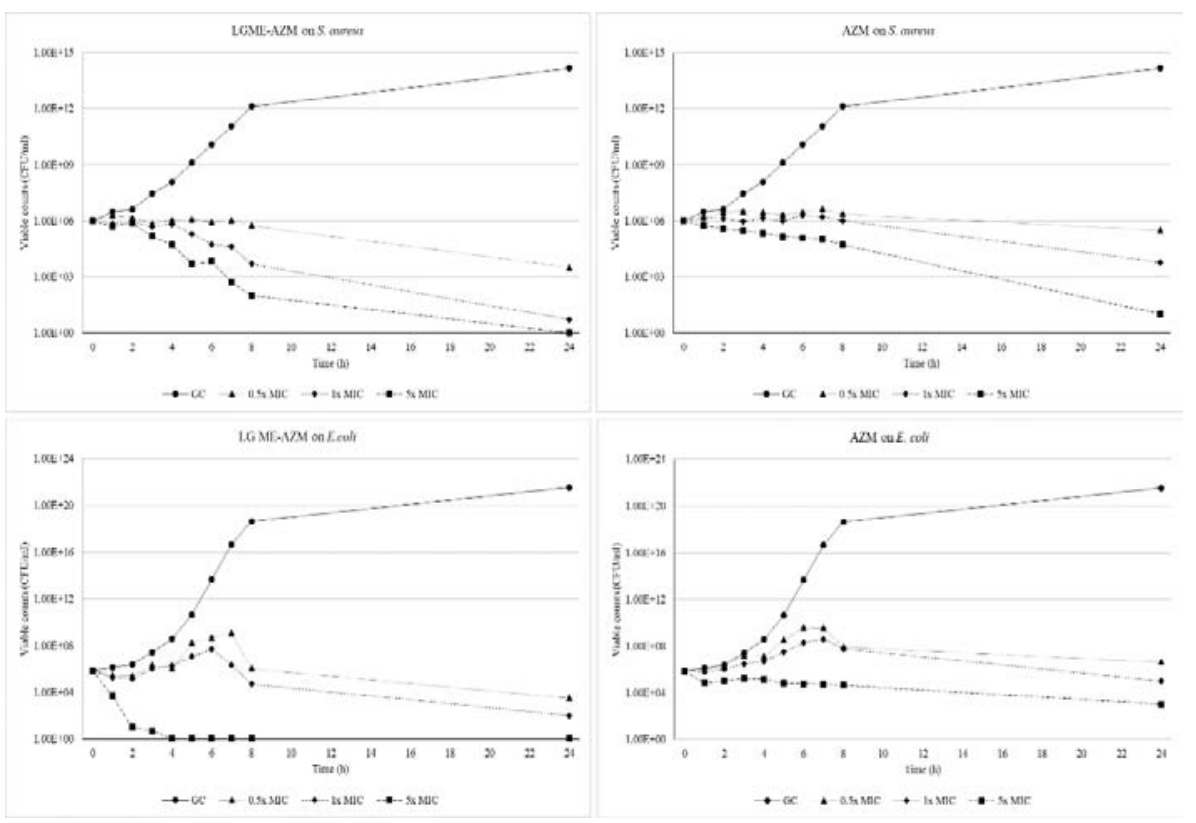

Fig. 5: Time-kill kinetics of LGME-AZM (1:4) and AZM pure drug suspension against S. aureus and E. coli 


\section{Determination of cell viability}

The cell viability or morphological alterations in the cell membrane of the treated bacteria was validated using $\mathrm{AO}$ and $\mathrm{EtBr}$ staining assay. Necrotic and apoptotic cells were differentiated from normal live bacteria cells using these dyes under fluorescent microscopy. AO is a basic dye that stains both live and dead cells, whereas EtBr will stain only the bacterial cells which loses its membrane integrity [15]. Untreated bacterial live cells of S. aureus (fig. 6a) and E. coli (fig. 6b) appears fluorescent green in color, which illustrates the staining with AO. After the interaction of bacterial strains with $1 \mathrm{x}$ LGME-
AZM, it appears red in color (fig. 6c and fig. 6d). The prepared slides were observed under a fluorescence microscope at $100 \mathrm{X}$ magnification. This signifies the antibacterial activity of the optimized ME formulation with AZM in damaging the bacterial cell membrane, which in turn leads to cell death. The ME droplet has the capability to fuse with lipid bilayer in the cell membrane of the bacterial pathogens and disrupts the cell membrane, and thereby impair the membrane integrity [43]. This causes lysis and death of the cell treated with ME. The alterations in the cell membrane changes the permeability and lead to the subsequent release of the intracellular components [44].
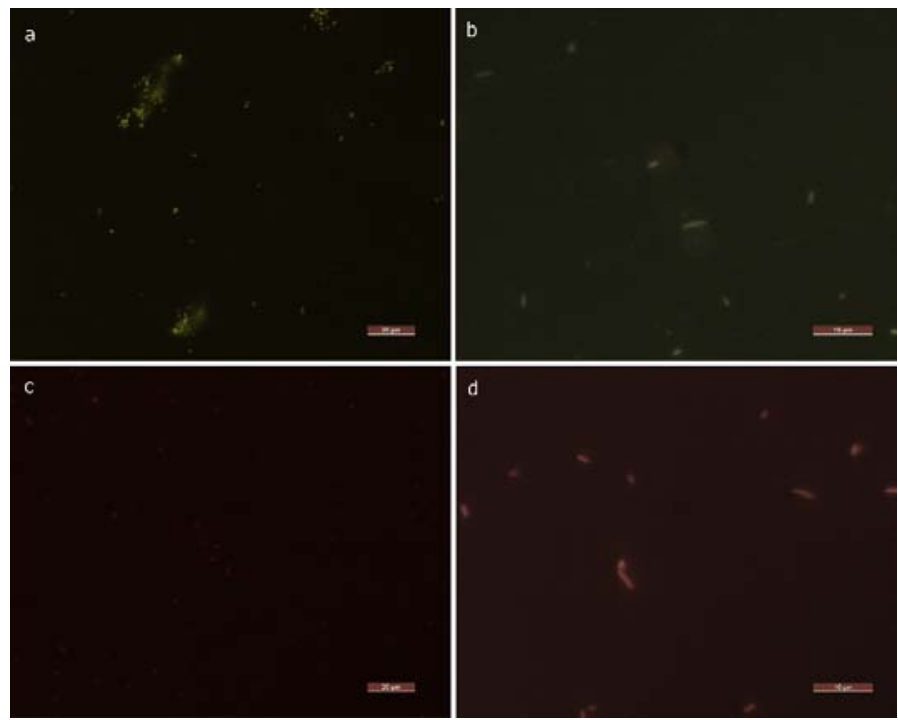

Fig. 6: Fluorescent micrographs of $\mathrm{AO}$ and EtBr double-stained bacterial strains to access the cell viability (i) Bacterial strains without treatment (control): (a) S. aureus, and (b) E. coli. (ii) Bacterial strains treated with 1x MIC of LGME-AZM (1:4) (c) S. aureus (d) E. coli

\section{Cell damage study by SEM}

Visual assessment of cell damage to bacteria provides definitive evidence to the antibacterial activity of the ME formulation against pathogenic bacterial strains. Bacterial cells treated with LGME-AZM at 1x MIC demonstrated considerable morphological changes in the cell structure compared to the untreated bacterial strain observed under a scanning electron microscope (SEM). The treated cells of S. aureus and E. coli showed morphological changes in comparison to the untreated cells. The morphology of control cells of $S$. aureus and E. coli was smooth, with intact cell membrane (fig. 7a and 7c). After exposure to the optimized LGME-AZM, the cells were remarkably deteriorated, showing an irregularity in shape and structure of the cells (fig. 7b and $7 d)$. This clearly explains the leakage of the cytoplasmic material of the bacterial cells. Tyagi et al. observed that E. coli treated with LG oil showed aggregation and deformities [45]. Korenblum et al. also stated that both LG oil and its major component, citral showed an immediate killing effect against sulfate reducing bacteria, suggesting that citral was responsible for the antibacterial activity of LG oil [46]. The SEM micrographs explains that the LGME-AZM formulation in comparison with the pure drug AZM has an enhanced antibacterial property against pathogenic bacterial strains.
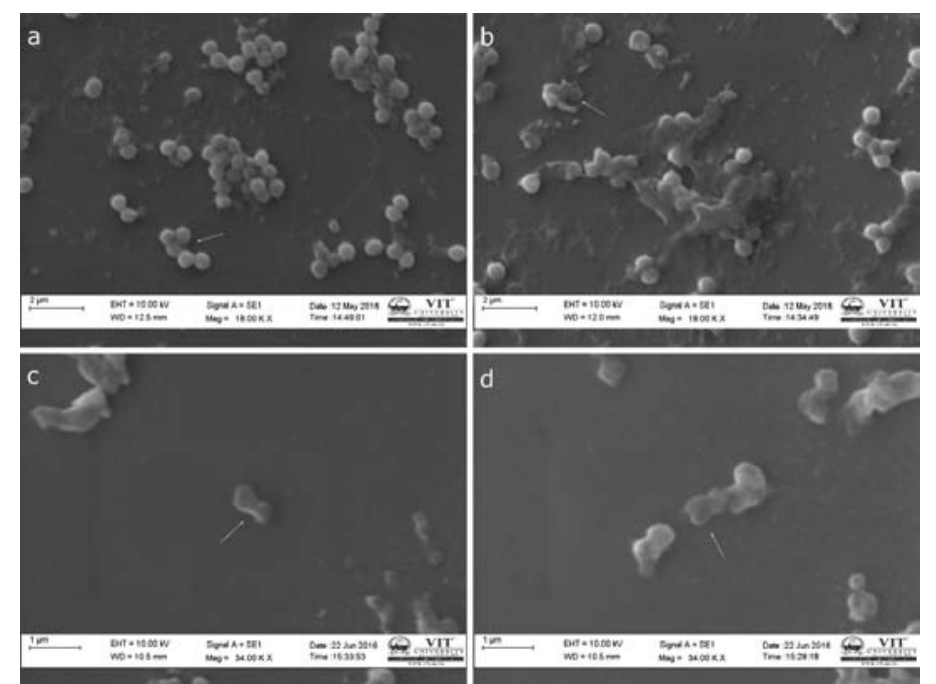

Fig. 7: SEM images: (i) S. aureus-(a) Untreated control (b) Treated with 1x MIC of LGME-AZM (1:4); (ii) E. coli-(c) Untreated control and (d) Treated with 1x MIC of LGME-AZM (1:4). Magnification at 18KX for S. aureus and 34KX for E. coli 


\section{Toxicity studies}

\section{(a) In vitro toxicity testing}

PBMC's have a major role in human defense mechanism. They are nucleated cells, consist of lymphocytes and monocytes. The cultured lymphocytes were isolated to analyse the in vitro toxicity estimation of the prepared ME. The cytotoxicity of ME was interpreted by calculating the percentage of viable cells after interaction with the ME formulation and its individual components. The cytotoxicity of ME was illustrated by the decline in cellular viability of lymphocytes in a dose-dependent manner (fig. 8). The contact of ME with the human lymphocytes have the ability to impair the functional role of mitochondria, and the cytotoxicity was generally due to the initiation of cell death through the mitochondrial-dependent pathway [47]. The cytotoxicity study done on human lymphocytes displays that the ME at lower concentration $(<25 \%)$ shows lesser toxicity to the cells compared to the higher concentrations, showing more than $50 \%$ of viable cells. This result confirms that the LG oil with acidic $\mathrm{pH}$ was not found to be highly toxic to lymphocytes at a lower concentration. In ME, an aqueous solution (water) takes the major portion with only 5\% of LG oil. LGME-AZM prepared with the maximum solubility of the drug in LG oil, and the toxicity testing determines lesser toxicity compared to the control. This confirms the intake of LG oil based ME to be orally safe in ME form.

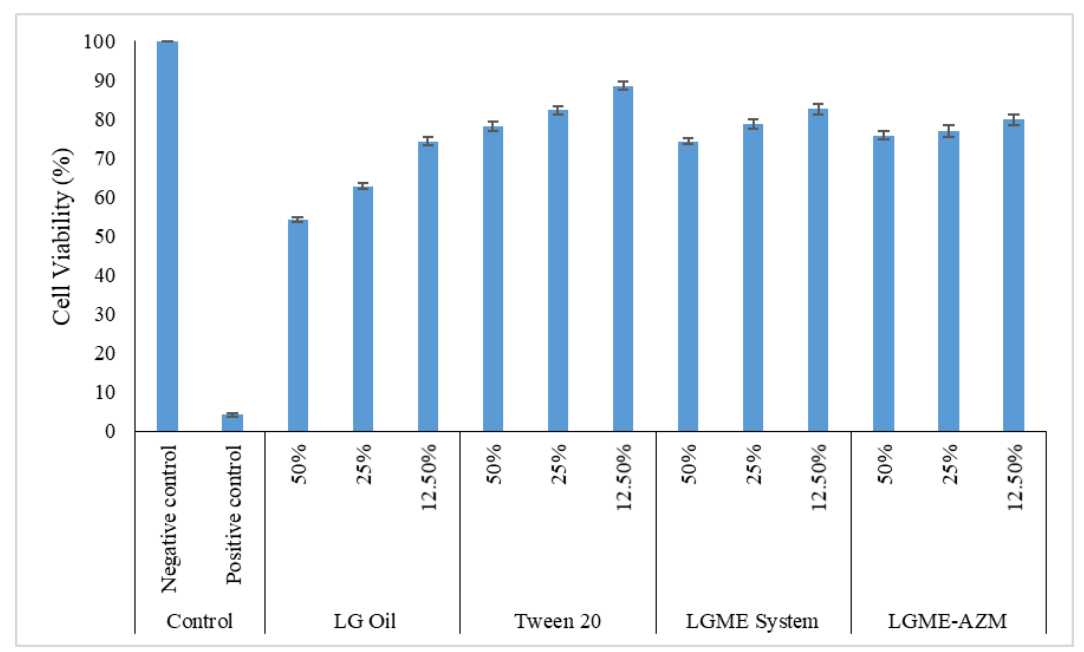

Fig. 8: Cytotoxicity estimation for the cellular viability of human lymphocytes by MTT assay

\section{(b) In vivo acute and sub-acute toxicity testing}

Male Wistar rats were used for in vivo toxicity assessment. From the results obtained from all experimental group along with the healthy control, there were no abnormalities observed in physical appearances such as scabies, mucoid or soft stool, hair loss, soft or mucoid stool, and decreased defecation. During the experimental process, the initial and final body weight of all the animals showed no abnormal variations. The enzyme activities of liver and kidney parameters were estimated from the blood collected, and the result determines that the values were similar as that of the healthy group of Wistar rats, as shown in table 5. Haematological parameters showed no abnormalities compared with the healthy control, as shown in table 6. Histopathological evaluation of liver and small intestine samples after consumption of microemulsion comprise to control group did not show any major abnormalities in organs and tissues. The dosage groups and the healthy group showed normal parenchymal structures with cords of hepatocytes observed with no major changes when compared to the normal control group. This confirms that the ME dosage group of animals showed no changes in structural and histopathological properties in small intestine and liver (fig. 9) compared to the normal healthy rats.

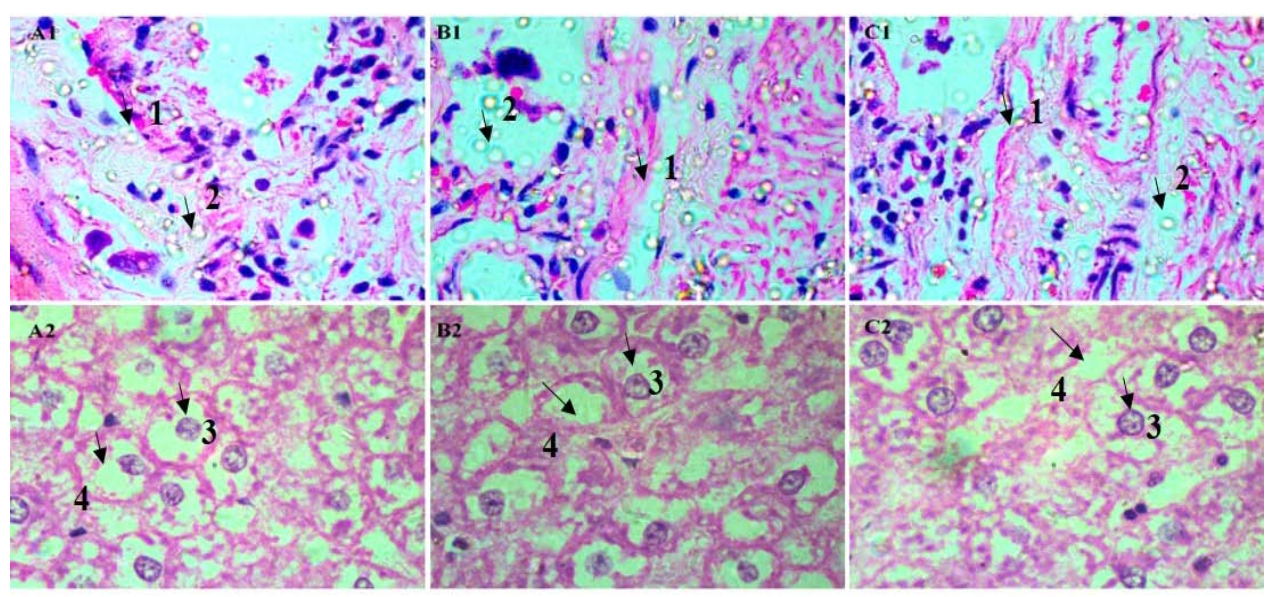

Fig. 9: In vivo toxicity testing. $\mathrm{H}$ and $\mathrm{E}$ stained section of small intestine (Top) and liver (bottom) of three animal groups: Normal Controls treated with saline $(\mathrm{A1}, \mathrm{A2})$, dosage groups treated with LGME system (B1, B2), and dosage groups treated with LGME-AZM (C1, C2).

(Magnification at 400X). Cellular morphology was observed with no abnormalities as marked: 1-Simple columnar epithelium, 2Cytoplasm of goblet cells-mucin containing secretory vesicles, 3-Hepatocytes, 4-Central lobular vein 
Table 5: Biochemical parameters in wistar rats

\begin{tabular}{llll}
\hline Groups & ALT (IU/l) & AST (IU/l) & Creatinine (mg/d) \\
\hline Control & $30.11 \pm 3.24$ & $79.19 \pm 9.28$ & $0.41 \pm 0.02$ \\
LGME system & $32.14 \pm 2.79$ & $78.34 \pm 11.32$ & $0.42 \pm 0.02$ \\
LGME-AZM & $33.26 \pm 3.36$ & $77.5 \pm 9.78$ & $0.38 \pm 0.02$ \\
\hline
\end{tabular}

(ALT-Alanine transaminase, AST-Aspartate transaminase; *Values with mean \pm SD n = 6)

Table 6: Hematological parameters in Wistar rats

\begin{tabular}{lllll}
\hline Groups & Hb (gm\%) & Total WBC count (cells/cu. mm) & RBC count (millions/cu. mm) & Platelets count (lakhs/cu. mm) \\
\hline Control & $18.2 \pm 0.16$ & $8900 \pm 101.98$ & $6.02 \pm 0.05$ & $2.61 \pm 0.01$ \\
LGME system & $17.1 \pm 0.24$ & $10103 \pm 81.78$ & $5.70 \pm 0.08$ & $2.44 \pm 0.04$ \\
LGME-AZM & $17.3 \pm 0.09$ & $8303 \pm 68.4$ & $5.73 \pm 0.16$ & $2.14 \pm 0.09$ \\
\hline
\end{tabular}

(Hb-Hemoglobin, WBC-White blood cell, RBC-Red blood cell; *Values with mean \pm SD n = 6)

\section{CONCLUSION}

The current work describes a lemongrass oil-based microemulsion system with azithromycin (LGME-AZM), formulated with low-energy methods, to obtain small droplets of uniform size, minimum surfactant concentration, and good thermodynamic stability for pharmaceutical application as a drug delivery vehicle to treat bacterial infections against microorganisms. The LG oil ME possesses potent anti-bacterial activity, which makes it a safer system for solubilizing hydrophobic antimicrobial drugs to enhance its antibacterial activity, thus paving the way to limit high drug dosage concentration. Toxicity studies confirm the optimized ME to be safer for oral intake, and thus this paves the major impact as an oral drug delivery system by increasing the efficacy of the lipophilic drug.

\section{ACKNOWLEDGMENT}

We thank VIT, Vellore for providing chemicals, equipment, and facilities needed to complete this work.

\section{AUTHORS CONTRIBUTIONS}

All the author have contributed equally

\section{CONFLICT OF INTERESTS}

\section{Declared none}

\section{REFERENCES}

1. Sareen S, Mathew G, Joseph L. Improvement insolubility of poor water-soluble drugs by solid dispersion. Int J Pharma Investig 2012;2:12-7.

2. Kumar A, Sharma S, Kamble R. Self-emulsifying drug delivery system (SEDDS): future aspects. Int J Pharm Pharm Sci 2010;2:7-13.

3. T Lalwani J, Thakkar VT, Patel HV. Enhancement of solubility and oral bioavailability of ezetimibe by a novel solid self-nano emulsifying drug delivery system (SNEDDS). Int J Pharm Pharm Sci 2013;5:513-22.

4. Pujara ND. Self-emulsifying drug delivery system: a novel approach. Int J Curr Pharm Res 2012;4:18-23.

5. Kreilgaard M. Influence of microemulsions on cutaneous drug delivery. Adv Drug Delivery Rev 2002;54:S77-98.

6. Dixit GR, Mathur V. Microemulsions: a platform for improvement of solubility and dissolution of poorly soluble drugs. Asian J Pharm Clin Res 2015;8:7-17.

7. Onawunmi GO. Evaluation of the antimicrobial activity of citral. Lett Appl Microbiol 1989;9:105-8.

8. Moore Neibel K, Gerber C, Patel J, Friedman M, Ravishankar S. Antimicrobial activity of lemongrass oil against Salmonella enterica on organic leafy greens. J Appl Microbiol 2012;112: 485-92.

9. Silva CdBd, Guterres SS, Weisheimer V, Schapoval EE. Antifungal activity of the lemongrass oil and citral against candida spp. Braz J Infect Dis 2008;12:63-6.

10. Tyagi R, Sharma G, Jasuja ND, Menghani E. Indian medicinal plants as an effective antimicrobial agent. J Crit Rev 2016;3:69-71.
11. Mazzei T, Mini E, Novelli A, Periti P. Chemistry and mode of action of macrolides. J Antimicrob Chemother 1993;31:1-9.

12. Champney WS, Burdine R. Azithromycin and clarithromycin inhibition of $50 \mathrm{~S}$ ribosomal subunit formation in Staphylococcus aureus cells. Curr Microbiol 1998;36:119-23.

13. Luke DR, Foulds G. Disposition of oral azithromycin in humans. Clin Pharmacol Ther 1997;61:641-8.

14. Shafiq S, Shakeel F, Talegaonkar S, Ahmad FJ, Khar RK, Ali M. Design and development of oral oil in water ramipril nanoemulsion formulation: in vitro and in vivo assessment. J Biomed Nanotechnol 2007;3:28-44.

15. Nirmala MJ, Mukherjee A, Chandrasekaran N. Improved efficacy of fluconazole against candidiasis using bio -based microemulsion technique. Biotechnol Appl Biochem 2013;60:417-29.

16. Prajapati ST, Joshi HA, Patel CN. Preparation and characterization of self-micro emulsifying drug delivery system of olmesartan medoxomil for bioavailability improvement. J Pharm 2012. http://dx.doi.org/10.1155/2013/728425

17. Syed HK, Peh KK. Identification of phases of various oil, surfactant/co-surfactants and water system by ternary phase diagram. Acta Pol Pharm 2014;71:301-9.

18. Nasr A, Gardouh A, Ghorab M. Effect of oils, surfactants and cosurfactants on phase behavior and physicochemical properties of self-nanoemulsifying drug delivery system (SNEDDS) for Irbesartan and Olmesartan. Int J Appl Pharm 2016;8:1-9.

19. Liu Z, Wang X, Yao K, Du G, Lu Q, Ding Z, et al. Synthesis of magnetite nanoparticles in W/O microemulsion. J Mater Sci 2004;39:2633-6.

20. Shafiq S, Shakeel F, Talegaonkar S, Ahmad FJ, Khar RK, Ali M. Development and bioavailability assessment of ramipril nanoemulsion formulation. Eur J Pharm Biopharm 2007; 66:227-43.

21. Nirmala MJ, Shivashankar M, Ernest V, Mukherjee A, Chandrasekaran N. Physico-chemical characterization of ramipril using clove oil based microemulsion drug delivery system. Nanomed Nanobiol 2014;1:43-50.

22. Marques MR, Loebenberg $\mathrm{R}$, Almukainzi M. Simulated biological fluids with possible application in dissolution testing. Dissolution Technol 2011;18:15-28.

23. Solanki SS, Sarkar B, Dhanwani RK. Microemulsion drug delivery system: for bioavailability enhancement of ampelopsin. ISRN Pharm 2012. Doi:10.5402/2012/108164.

24. Elshikh M, Ahmed S, Funston S, Dunlop P, McGaw M, Marchant $\mathrm{R}$, et al. Resazurin-based 96-well plate microdilution method for the determination of the minimum inhibitory concentration of biosurfactants. Biotechnol Lett 2016;38:1015-9.

25. Barry AL, Craig WA, Nadler H, Reller LB, Sanders CC, Swenson JM. Methods for determining bactericidal activity of antimicrobial agents: approved guideline. NCCLS document M26-A; 1999. p. 19.

26. Sarker SD, Nahar L, Kumarasamy Y. Microtitre plate-based antibacterial assay incorporating resazurin as an indicator of cell growth, and its application in the in vitro antibacterial screening of phytochemicals. Methods 2007;42:321-4. 
27. Nogueira F, Diez A, Radfar A, Perez-Benavente S, do Rosario VE, Puyet A, et al. Early transcriptional response to chloroquine of the plasmodium falciparum antioxidant defence in sensitive and resistant clones. Acta Trop 2010;114:109-15.

28. Sugumar S, Ghosh V, Nirmala MJ, Mukherjee A, Chandrasekaran $\mathrm{N}$. Ultrasonic emulsification of eucalyptus oil nanoemulsion: antibacterial activity against Staphylococcus aureus and wound healing activity in wistar rats. Ultrason Sonochem 2014; 21:1044-9.

29. Boyum A. Isolation of mononuclear cells and granulocytes from human blood. Isolation of monuclear cells by one centrifugation, and of granulocytes by combining centrifugation and sedimentation at 1 g. Scand J Clin Lab Invest 1968;21:77-89.

30. Naravaneni R, Jamil K. In vitro cytogenetic studies of cypermethrin on human lymphocytes. Indian J Exp Biol 2006;44:233-9.

31. Spencer K. Analytical reviews in clinical biochemistry: the estimation of creatinine. Ann Clin Biochem 1986;23:1-25.

32. Kumar GP, Rajeshwarrao P. Nonionic surfactant vesicular systems for effective drug delivery-an overview. Acta Pharm Sin B 2011;1:208-19.

33. Patel V, Kukadiya H, Mashru R, Surti N, Mandal S. Development of microemulsion for solubility enhancement of clopidogrel. Iran J Pharm Res 2010;9:327-34.

34. Srinivas C, Sagar S. Enhancing the bioavailability of simvastatin using microemulsion drug delivery system. Asian J Pharm Clin Res 2012;5:134-9.

35. Lawrence MJ, Rees GD. Microemulsion-based media as novel drug delivery systems. Adv Drug Delivery Rev 2012;64:175-93.

36. Thakkar H, Nangesh J, Parmar M, Patel D. Formulation and characterization of lipid-based drug delivery system of raloxifene-microemulsion and self-micro emulsifying drug delivery system. J Pharm Bioallied Sci 2011;3:442-8.

37. Li X, Anton N, Ta TMC, Zhao M, Messaddeq N, Vandamme TF. Microencapsulation of nanoemulsions: novel trojan particles for bioactive lipid molecule delivery. Int J Nanomed 2011;6:1313-25.
38. Hunter RJ. Zeta potential in colloid science: principles and applications. 1st ed.: Academic Press; 2013.

39. Honary S, Zahir F. Effect of zeta potential on the properties of nano-drug delivery systems-a review (Part 2). Trop J Pharm Res 2013;12:265-73.

40. Woo BH, Kostanski JW, Gebrekidan S, Dani BA, Thanoo B, DeLuca PP. Preparation, characterization and in vivo evaluation of 120-day poly (D, L-lactide) leuprolide microspheres. J Controlled Release 2001;75:307-15.

41. Mandal S, Mandal SS. Research paper microemulsion drug delivery system: a platform for improving the dissolution rate of the poorly water-soluble drug. Int J Pharm Sci Nanotech 2011;3:1214-9.

42. Norcia L, Silvia A, Hayashi S. Studies on the time-kill kinetics of different classes of antibiotics against veterinary pathogenic bacteria including Pasteurella, Actinobacillm and Escherichia coli. J Antibiot 1999;52:52-60.

43. Baker Jr JR, Hamouda T, Shih A, Myc A. Non-toxic antimicrobial compositions and methods of use, U. S. Patent No. 6,559,189; 2003.

44. Sugumar S, Mukherjee A, Chandrasekaran N. Eucalyptus oil nanoemulsion-impregnated chitosan film: antibacterial effects against a clinical pathogen, Staphylococcus aureus in vitro. Int J Nanomed 2015;10:67.

45. Tyagi AK, Malik A. Morphostructural damage in food-spoiling bacteria due to the lemongrass oil and its vapour: SEM, TEM, and AFM investigations. Evid Based Complement Alternat Med 2012. Doi:10.1155/2012/692625.

46. Korenblum E, Regina de Vasconcelos Goulart F, de Almeida Rodrigues I, Abreu F, Lins U, Alves PB, et al. Antimicrobial action and anti-corrosion effect against sulfate reducing bacteria by lemongrass (Cymbopogon citratus) essential oil and its major component, the citral. AMB Express 2013;3:44.

47. Braun S, Gaza N, Werdehausen R, Hermanns H, Bauer I, Durieux $\mathrm{ME}$, et al. Ketamine induces apoptosis via the mitochondrial pathway in human lymphocytes and neuronal cells. $\mathrm{Br} J$ Anaesth 2010;105:347-54. 